Bangladesh J. Bot. 40(1): 23-27, 2011 (June)

\title{
EFFECTS OF PHOSPHORUS DEFICIENCY ON ACCUMULATION OF BIOCHEMICAL COMPOUNDS IN LENTIL (LENS CULINARIS MEDIK.)
}

\author{
Bimal Chandra Sarker ${ }^{*}$ and JL Karmoker \\ Department of Botany, University of Dhaka, Dhaka-1000, Bangladesh
}

Key words: Phosphorus deficiency, Accumulation, Biochemical compounds

\begin{abstract}
Phosphorus deficiency caused a decrease in the accumulation of reducing sugar in the leaves and stems but increased in the roots of lentil (Lens culinaris Medik.). Accumulation of insoluble protein was depressed in lentil following P-deficiency. Phosphorus deficiency increased proline and phenolic compounds in roots and stems and anthocyanin in leaves compared to control.
\end{abstract}

\section{Introduction}

Phosphorus is needed by young tissues and it performs a number of functions related to growth, development and metabolism. Despite its ubiquitous importance to plant metabolism, iP is one of the least available nutrients in many natural ecosystems (Barber 1980). Total soil phosphorus is often hundred fold more than the fraction of inorganic phosphorus available for uptake by crop plants and most of the phosphorus applied to field form complexes with iron and aluminum in acidic and calcium in alkaline soil and thus becomes unavailable to plants. Low phosphorus availability strongly limits plant productivity in tropical soils. The world phosphate institute classified $65 \%$ of 500 soil samples collected from 42 countries in the tropics as acutely deficient in phosphorus, $27 \%$ as moderately deficient. But only $8 \%$ of sample were classified as not deficient (Koala et al. 1988).

An increase in carbohydrate concentration in the root of bean is one of the first observed effects of phosphate starvation (Ciereszko et al. 1996). Khamis et al. (1990) showed that accumulation of sucrose increased in the root of maize plants due to phosphorus deficiency. In potato accumulation of non-reducing sugar in the root was increased at low -P (Mc-Arthur and Knowles1993). Li et al. (2004) reported that phosphorus deficiency resulted in an increase in $C^{12}$ assimilates in rice and more assimilates were distributed to the root. Omission of $\mathrm{P}$ from the growth medium caused an increase in the fructan concentration in barley. But there was little or no effect on the concentrations of starch, sucrose, glucose and fructose (Wang et al. 1997).

Usuda and Shimogawara (1995) reported that in phosphorus deficient maize, soluble and insoluble protein contents decreased as compared to that of control plants. In many plants, Pdeficiency enhanced production and root exudation of phenolic compounds (Dinkelaker et al. 1995). Phosphorus deficiency caused an increase in anthocyanin pigment content in the leaves of barley (Hamy 1983).

Reports on effects of phosphorus deficiency stress on biochemical changes in lentil are very rare. Therefore, the present investigation was undertaken to study the effects of phosphorus deficiency on the accumulation or distribution of reducing sugar, insoluble protein, proline, phenolic compounds and anthocyanin in lentil.

\section{Material and Methods}

Seeds of lentil (Lens culinaris Medik. var. Barimasur-4) 2n=14, were collected from Bangladesh Agricultural Research Institute, Joydebpur, Gazipur. Plants were grown in with or without phosphorus culture solution for biochemical study. Seedlings were subjected to phosphorus deficiency for 7, 14, 21 and 28 days in triplicates. Reducing sugar was determined by

*Department of Botany, Ananda Mohan College, Mymensingh-2200, Bangladesh. <bimal_ict111@ yahoo.com>. 
Somogyi-Nelson method (Nelson 1944, Somogyi 1952). Insoluble protein estimation was done according to Lowry et al. (1951), while proline was estimated following the method of Bates et al. (1973), total phenolic compounds according to Malik and Singh (1980) and anthocyanin according to Sims (2003).

\section{Results and Discussion}

Phosphorus deficiency decreased accumulation of reducing sugars in the stems and leaves but increased in roots of lentil (Fig. 1a,b,c). The increase in the amount of reducing sugar in the roots with concomitant decrease in the stems and leaves might be due to increased translocation of reducing sugars from the leaves to roots. The decrease is more pronounced in leaves. Phosphorus
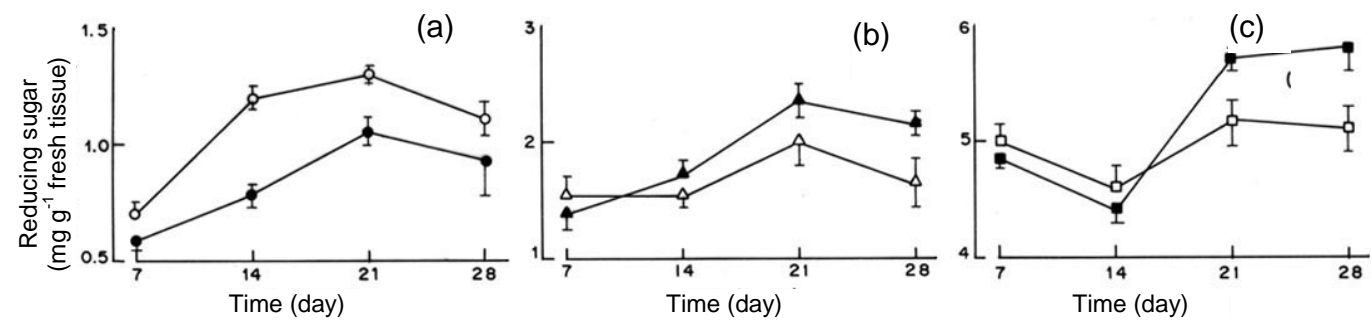

Fig. 1. Effects of phosphorus deficiency on the accumulation of reducing sugar in (a) roots, (b) stems and (c) leaves of lentil plants grown in solution culture. Solid symbols indicate with $\mathrm{P}$ and open symbols indicate without P. Each value is the mean of three replicates and bars represent standard error.

is indirectly involves in synthesis of protein. Therefore without P protein accumulation declined (Witham et al. 1971). These results are in conformity with Rychter and Randall (1994) who also found that in Phaseolus vulgaris, phosphorus deficiency increased reducing sugar in the root with concomitant decrease in the shoot. Sa and Israel (1995) reported that phosphorus deficiency caused a decrease in hexose and sucrose concentrations but an increase in the starch content in the root nodule of soybean due to impaired carbohydrate utilization.

Phosphorus deficiency inhibited the accumulation of insoluble proteins in the roots and the stems of lentil (Fig. 2a, b). Usuda and Shimogawara (1995) showed that low-P level decreased soluble protein contents in maize. Accumulation of reducing sugar declined in leaves (Fig. 1c) and that of insoluble protein also declined in the root and stem of lentil (Fig. 2a, b) at 14 days of treatment in both control and phosphorus deficiency. The decline of reducing sugar and insoluble protein may be due to increase in growth having rate of accumulation of these compounds constant.
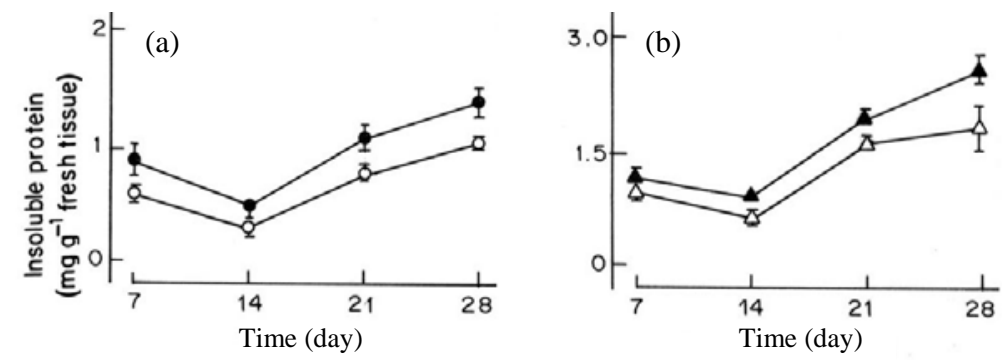

Fig. 2. Effects of phosphorus deficiency on the accumulation of insoluble protein in roots (a) and stems (b) of lentil plants at different period of treatment. Symbols as in Fig. 1. 
An increase in proline accumulation in the roots of lentil was observed from seven to 28 days of phosphorus deficiency treatment (Fig. 3a). Similar stimulation of proline accumulation was observed in the stems of phosphorus deficient lentil seedlings (Fig. 3b). This result is an agreement with that of Al-Karaki et al. (1996) who reported increased proline accumulation in the leaves of sorghum and bean under phosphorus deficiency stress.
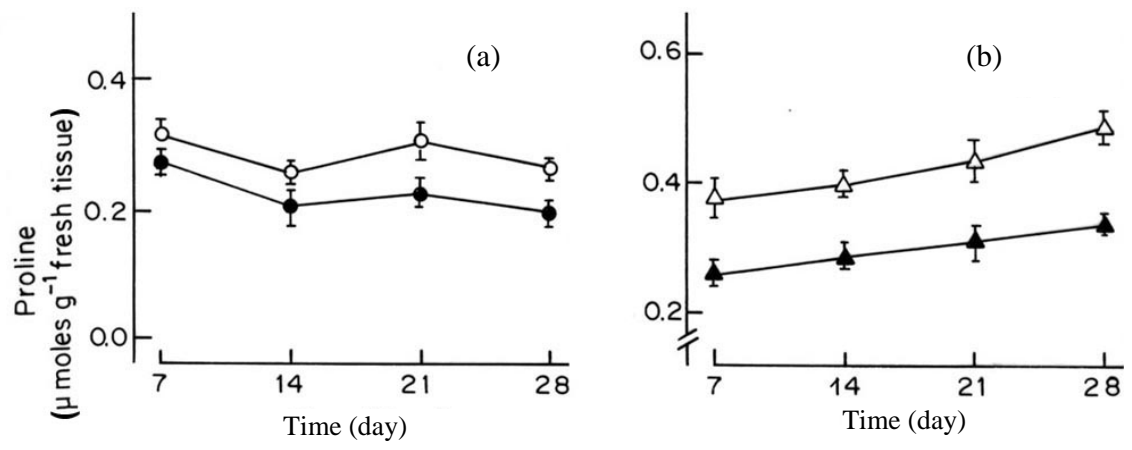

Fig. 3. Effects of phosphorus deficiency on the accumulation of proline in roots (a) and stems (b) of lentil plants at different period of treatment. Symbols as in Fig. 1.

Phosphorus deficiency resulted in an increase in total phenolic-compounds in intact lentil and more phenolic compounds were distributed to the root (Fig. 4a, b). This result is consistent with that of Neumann et al. (1998) who reported that in white lupin, phosphorus deficiency increased secretion of phenolic compounds in the root. Phenolics formed relatively stable chelates with $\mathrm{Fe}^{3+}$ and $\mathrm{Al}^{3+}$, thereby increasing the solubility Fe-P and Al-P releasing $\mathrm{P}$ for absorption by plants (Ae et al. 1990).
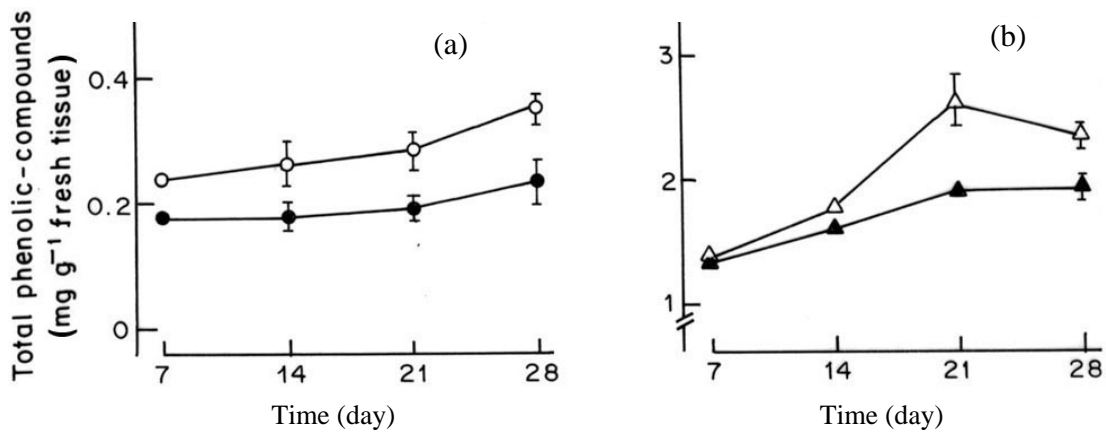

Fig. 4. Effects of phosphorus deficiency on the accumulation of total phenolic compounds in roots (a) and stems (b) of lentil plants at different period of treatment. Symbols as in Fig. 1.

Accumulation of total anthocyanin was increased in the leaves of lentil from seven to 14 days of phosphorus deficiency treatment and this stimulatory effect was sustained up to 28 day of treatment (Fig. 5). Earlier, Raise (2002) reported increased anthocyanin pigment accumulation in the leaves of apple and pear following phosphorus deficiency. It is suggested that phosphorusdeficiency induced-stimulation of anthocyanin may act as an indicator of P-deficiency stress. 


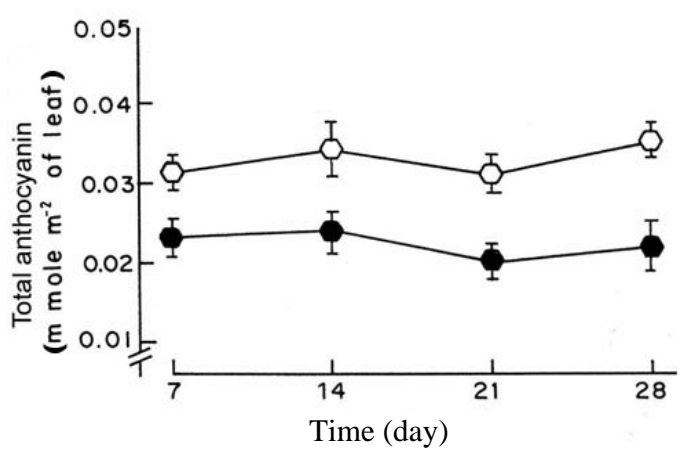

Fig. 5. Effects of phosphorus deficiency on the accumulation of total anthocyanin in leaves of lentil plants at different periods of treatment. Symbols as in Fig. 1.

\section{References}

Ae J, J Arikhara, K Okada, T Yoshinhara and C Johansen 1990. Phosphorus uptake by pigeon pea and its role in cropping system of the Indian subcontinents. Sci. 248: 477-480.

Al-Karaki GN, RB Clark and CY Sullivan 1996. Phosphorus nutrition and water stress effects on proline accumulation in sorghum and bean. Plant Physiol. 148: 745-751.

Barber BA 1980. Soil-plant interaction in the phosphorus nutrition of plants. In: Role of phosphorus in Agriculture, FE Khaswnch (Ed.), pp. 591-615. Am. Soc. Agro. Madison.

Bates LS, RP Waldren and D Teari 1973. Rapid determination of free proline for water stress studies. Plant Soil 39: 205-207.

Ciereszko I, A Gniazdowska, M Mikulska and AM Rychter 1996. Assimilate translocation in bean plants (Phaseolus vulgaris L.) during phosphate deficiency. Plant Physiol. 149: 343-348.

Dinkelaker B, C Hengeler and H Marschner 1995. Distribution and function of proteoid roots. Bot. Acta. 108: $183-200$.

Hamy A 1983. Effect of phosphorus deficiency on pigments of barley leaves. Comptes-Rendus des Seances de-1 'Academie-d' Agriculture de France 69: 935-943.

Khamis S, S Chaillou and T Lamaze 1990. $\mathrm{CO}_{2}$ assimilation and partitioning of carbon in maize plants deprived of orthophosphate. J. Expt. Bot. 41: 1619-1625.

Koala S, JR Sims, H El-Altar and M El-Halfawi 1988. Phosphorus deficiency in the semi-arid tropics and implications for grain legume production. In: World crops, cool season legumes, R.J. Summerfield (Ed), pp. 205-21. Kluwer Academic Publishers, London.

Li F, XH Pan, SY Liu, MY Li and FS Yang 2004. Effects of phosphorus deficiency stress on root morphology and nutrient absorption of rice cultivars. Acta-Agronomica-Sinica 30: 538-442.

Lowry OH, NJ Rosebrough, AL Farr and RJ Randall 1951. Protein measurement with the Folin-Phenol reagent. J. Biol. Chem. 193: 266-275.

Malik CP and MB Singh 1980. Plant enzymology and histoenzymology. Kalyani Publishers, New Delhi. 286 pp .

Mc-Arther DJ and NR Knowles 1993. Influence of vesicular-arbuscular mycorrhizal fungi on the response of potato to phosphorus deficiency. Plant Physiol. 101: 147-160.

Nelson N 1944. A photometric adaptation of the somogyi method for determination of glucose. J. Biol. Chem. 153: 375-380.

Neumann G, E George and Roemheld 1998. White lupin a model plant to study mechanisms involved in root-induced mobilization of sparingly available P-source. Plant Soil 211: 121-130.

Raise JT 2002. Phosphorus deficiency symptoms in leaves of apple and pear trees as influenced by available soil phosphorus. Commun. Soil Sci. Plant Anal. 33: 461-477. 
Rychter AM and DD Randall 1994. The effect of phosphate deficiency on carbohydrate metabolism in bean roots. Plant Physiol. 91: 383-388.

Sa TM and DW Isreal 1995. Nitrogen assimilation in nitrogen-fixing soybean plants during phosphorus deficiency. Crop Sci. 35: 814-820.

Sims DA 2003. Estimating anthocyanin concentration using hyperspectral reflectance. Ecol. Soc. Am. meetings, Spokane.

Somogyi M 1952. Notes on sugar determination. J. Biol. Chem. 195: 19-23.

Usuda H and K Shimogawara 1995. Phosphate deficiency in Maize: changes in the two-dimensional electrophoretic patterns of soluble proteins from second leave blades associated with induced senescence. Plant Cell Physiol. 36: 1149-1155.

Wang C, JE Tillberg, CJ Pollock and JF Farrar 1997. Effects of short-term phosphorus deficiency on carbohydrate storage in sink and source leaves of barley (Hordium vulgare). New Phytologist 136: 131-135.

Witham FD, DF Blaydes and RM Devlin 1971. Experiments in plant physiology. Van Nostand Reinhold Co., New York

(Manuscript received on 17 July, 2010; revised on 3 November, 2010) 